\title{
Formative Assessment in Classrooms: Operational Procedures
}

\author{
Liqiu Wei \\ Department of Foreign Languages and literature, Hechi University, Yizhou, Guangxi, China \\ Email: lisawlq@yahoo.com.cn
}

\begin{abstract}
Seen as "assessment for learning", formative assessment has attracted the attention of more and more educators and practitioners around the globe. Based on the writer's experience with the implementation of formative assessment in her classrooms in China, this article describes the operational procedures of formative assessment use in classrooms. It first presents guidelines for the proportion of summative assessment and formative assessment in the course's final scores, for formative assessment plan formulating and for feedback and grading, then describes the procedures, from need analysis and goal setting to formative assessment plan drafting, communicating, implementing and evaluating and revising.
\end{abstract}

Index Terms - formative assessment, college English teaching, feedback, self-assessment

\section{INTRODUCTION}

Around the globe, educators are beginning to pay more and more attention to the assessments teachers use in classrooms on a daily basis as a powerful lever for raising student achievement. Many nations, such as New Zealand, Scotland, England, the United States have even developed government-sponsored "Assessment for Learning" programs (Olson, 2005). Formative assessment (FA), characterized by multi-assessors, rich and varied assessing techniques and strategies, multi-aspects in contents, and being process-focused and personalized, is seen as alternative assessment for improvement of students' learning. As a result, over the past two decades, a substantial body of research has been conducted to study FA globally (e.g., Gibbs \& Simpson, 2004; Pausch \& Popp, 1997; Black \&William, 1998a/b; Ministry of Education, New Zealand, 1994; Guo \& Yang, 2003; ARG, 1999; Xu, 2003; xue 2006; Zou \& Cai, 2006).

Motivated and inspired by Black and William's (1998a, b) research review findings ${ }^{1}$ and Tan's (2004) empirical research results ${ }^{2}$, I have tried too FA use in my English classrooms for three semesters with a total number of 227 student participants, most of whom were unmotivated and low achievers in English. My circular action research results do prove that the efforts are worthwhile and FA is indeed "assessment for learning". Its appropriate use can help students form positive view of learning and assessment, improve their motivation and self confidence, foster their independent learning and enhance their individualized use of effective learning strategies and methods, and if used persistently and properly, the impact on their English achievements can be hopefully achieved.

However, due to FA's own acknowledged limitations such as time-consuming, labor extensive, low reliability (Xu, 2003; Zou \& Cai, 2006; xue 2006), technical and professional (Xu, 2003), and medium-long-term effect, the potential advantages and empowering impact on students' learning will not occur spontaneously. In order for FA to be effective in practice, besides collaborative efforts among colleagues and necessary special training beforehand, special attention needs to be paid to the operational process. In this article, based on my own research, I will describe the operational guidelines and procedures of FA implementation in classrooms, focusing on FA plan formulating, FA grading and implementing process.

\section{GUIDELINES}

\section{A. Guidelines for the Proportion of Summative Assessment and FA in Course Final Scores}

Considering the washback effect of testing upon learning, and due to the fact that formative assessment and summative assessment are interactive and they seldom stand alone in construction or effect (Gipps, McCallum \& Hargreaves, 2000), when doing assessment, attention needs to be paid not only to outcomes but also and equally to the experiences that lead to those outcomes (Pausch \& Popp, 1997).Therefore, for the purpose that assessment is incorporated systematically into teaching strategies and practices, I propose the principle of combining summative

\footnotetext{
${ }^{1}$ Black and William conducted an extensive research review of 250 journal articles and book chapters winnowed from a much larger pool to determine whether formative assessment raises academic standards in the classroom, finding that efforts to strengthen formative assessment produce significant learning gains as measured by comparing the average improvements in the test scores of the students involved in the innovation with the range of scores found for typical groups of students on the same tests. Effect sizes ranged between 0.4 and 0.7 , with formative assessment apparently helping low-achieving students, including students with learning disabilities, even more than it helped other students.

2 Tan's (2004) empirical research has revealed that formative assessment is more effective than summative assessment to aid adult learners to master meta-cognitive strategies, strengthen students 'motivation, form positive affect and improve students' performance in tests
} 
assessment and formative assessment in course scoring. In other words, summative and formative assessment should stay alongside in teaching and learning process and each weigh half in the terminal grade of the learning subject. To be specific, summative assessment (e.g., Unit tests, final exams) and formative assessment (such as group work involvement, questioning and answering, observations, portfolios) each account for 50 points in students' semester final grade for the course. The rationale for so doing is the fact that all students at all educational levels care about the final grades for any subject or course they learn. Making formative assessment weigh 50 percent can contribute to students' awareness of their daily learning and striving for better results in and throughout all learning activities. In addition, although there are many limitations and disadvantages with summative assessment, it still plays an important role and cannot be left out in educational settings, especially in China. What we need to do is adopt formative assessment as a necessary supplementary to summative assessment to impact and maximize students learning process.

\section{B. Guidelines for Formative Assessment Plan Formulating}

A practical and feasible FA plan is a crucial step for the effective use of FA to improve learning. Therefore, when formulating the formative assessment plan, we need to take some factors into consideration. As far as my own research is concerned, I mainly took into account flexibility, integration, practicality, feasibility and variety based on the requirements of good assessment (e.g., Gibbs and Simpson's 11 conditions, 2004; Pausch \& Popp's nine principles, 1997; Black \& William's five factors, 1998b). By flexibility, I mean that the plan can be adjusted in the implementing process and that students can have their own options to some degree. Variety and integration refer to the use of various kinds of learning activities and of assessment strategies and techniques, which may encourage students to use a variety of learning strategies to attain their goals and develop their integrated skills. The assessing plan should consist of and specify assessing/learning items, and contents to be covered, tools or strategies used, assessing agents for each item. And the learning activities must be a combination of input and output items, of cognitive and meta-cognitive ones, of required and optional ones, of individual work and collaborative projects. Required items refer to those activities designed to achieve the shared instructional goal of teacher and all students, and the optional items are for individual students to choose according to their own needs and interest, which beneficially provide a good self development platform for them. Except for testing items, peer/ self assessment is required in nearly every item. And self assessment is highly valued. Furthermore, the assessing system and items vary from semester to semester according to different semester teaching focuses and goals.

\section{Guidelines for Feedback and Grading}

In order for students to better monitor and direct their own learning and for them to see every effort they take counts, feedback and grading should be given to FA items. The general feedback-giving and grading principle for FA goes as follows:

Written feedback is combined with oral feedback, letter grading combined with scoring; multi-dimensional assessment, with self assessment first, peer assessment next, and teacher assessment last (not with every activity/item of course, it depends); with encouragement focused, positive comments are preferable over negative ones, advice over criticism; and emotional factors over cognitive factors. During scoring, being general is preferable over being specific. So doing lies in the purpose of our using FA. For example, the ultimate purpose of our using formative assessment in College English teaching and learning is, by taking advantage of evaluation wash-back upon instruction, to enhance students' learning, reading, writing, and action through assessing. Besides, it is hoped that students can experience the fun of learning and the joy of success through the assessing process, and acquire linguistic and reflective skills, and other social skills such as how to cooperate with others, how to evaluate others in the experiencing process. Considering criticism (other than simply identifying deficiencies) is usually counterproductive (Crooks, 1988), we should always be generous with our praise and encouragement, giving them timely feedback about their every little progress. By so doing, we can help students experience the joy of success and motivate them to strive for next goal. As it were, introducing formative assessment into classrooms is a means, through which students learn to self-manage their own learning, promote their development. Assessment is never an end because our purpose is not to judge or select. As a result, we should pay more attention to the impact of the assessment on students than its validity or reliability.

For some activities or items such as oral presentation, collaboration performance and reading log, corresponding checklists or formats should be offered to students to use as success criteria in the process of learning activities.

As for the time for final grading of FA, it is desirable to be conducted at the end of the semester. We can design something like Final Formative Assessment Achievement Report (See the samples in appendix) for students to do self and collaborative assessment, with criteria checklist given. They just give a letter grade varying from $\mathrm{E}$ to $\mathrm{F}$, which stand for Excellence and Fair respectively, with V (very good), G (good), S (satisfactory) between. And the teacher, based on students' self and collaboration assessment results and observations, and by referring to students learning portfolios, give the final score for FA proportion in the course. The collaboration assessment team can be made up of either dormitory members or learning group members if any or class leaders team plus two or three student representatives.

\section{PROCEDURES}


The process of formative assessment goes as the following pattern:

Needs Analysis, semester instructional goal setting $\rightarrow$ formulating the assessment plan $\rightarrow$ distributing and explaining the plan sheets $\rightarrow$ Implementing the plan $\rightarrow$ evaluating and revising the plan $\rightarrow$ formulating a new plan for next circular research

\section{A. Needs Analysis and Semester Instructional Goal Setting}

The diversity of students' background, English levels and needs means that any FA plan should be based on needs analysis and curriculum requirements to set a practical goal and draft a feasible assessment plan. In addition, the identification by teacher and students of learning goals, intentions or outcome and the criteria for achieving these is one of the five key elements of FA. There are many ways to do needs analysis. We should choose appropriate methods with regard to students' different learning stages and course nature. For example, when teaching English to freshmen, before instruction begins, we may combine a diagnostic test and a questionnaire survey to collect relevant data such as their current state of English proficiency, their preferred classroom activities and their learning habits. The test results and the questionnaire survey findings may show us students' their expectations for course, their weaknesses and strengths in the four skills and other information we need, which serve as justifications for the planning of formative assessment plan.

\section{B. Formulating the Formative Assessment Plan}

Based on the needs analysis and teaching syllabus, we make our assessing plan. Still take my own research as example. In my three-semester's research, I made three responsive assessment plans for each section. The first assessment plan which served as a pilot study in the first section included 7 required items: attendance, preview, quizzes and homework, autonomous listening, recitation of New Concept English (Book III), extracurricular reading and study plan making and implementing. Other activities were encouraged. Many evaluated contents were covered, from attendance, linguistic competence to attitude, learning behavior, independent learning awareness, and awareness of strategy. The focus of this plan was on vocabulary and structure in response to students' needs. New Concept English (Book III) has been recognized as an effective learning source to improve grammar and vocabulary bank by many English authorities such as He Qixin and many English learners. Therefore, recitation of the texts from this book was required of the students because they were generally poor in grammar and vocabulary. All items involved students' self/peer assessment and teacher assessment.

The assessment plan for the second research section was more complete and more specific because it was formulated based on the practice of the first one. And the teacher's further knowledge about students after one semester's teaching also contributed a lot to the quality formulation of the second plan. In this plan, there were six required learning items: oral presentation as task-based learning, learning in classroom, homework, testing, response log for movie, and final reflections. Three optional items (reading, dialogue conversation, listening) and other optional items were also listed for their personalized choice. More extensive contents were included for evaluation, ranging from linguistic competence, thinking skills to team spirit. What's more important with this plan is that a very specific description about the rationale for each item was given and attached to the plan for student better understanding and action.

\section{Communicating the Formative Assessment Plan}

The next step we need to do is to print and distribute and explain the plan, item by item, to students, to ensure that every student has one copy to keep for their regular "visit" and that every student understands what and how and why to do so as to effectively guide their subsequent learning efforts, to minimize the problem of information gap between the teacher and students in terms of teaching goal through this formative assessment plan. In order to let every student have better understanding of every item, besides communicating in detail the learning intentions of each item to students in class, in my research, I also attached to the plan sheet very specific instructions about the use of and the rationale for each item. For example, the following description was given for the item "Journal Dialog": Writing: Dialogue Journals are written conversations between students and teachers. It integrates writing and reading as one. It is not only an efficient way to improve writing but also a platform for teacher-student communication in English. In particular, it provides a good opportunity of student-teacher communication for those who are not good at or don't want to speak face to face with the teacher. In your journal, you can write about anything you want to say, your study, your opinion of someone(including the teacher and his or her behavior, teaching methods, etc.), your success, trouble or even distress Just write and don't care about the grammar. You can write in a notebook or in computer (if you have any access to computers).

One thing should be mentioned here is that the plan is general one. There is still available room for improvement during the instructional process. So long as we do not stray away from our instructional goal, any adjustment is embraced because we always change for the better result.

\section{Implementing the Formative Assessment Plan}

With all preparations done, we should begin implementing the plan by integrating formative assessment strategies and techniques into our instructional process. At this stage, one thing--quality feedback needs to be given priority to. As Sutton (1998) put it, our feedback should 'be specific (both positive and critical); be descriptive (describing what the student said or did), rather than evaluative (involving a value judgment); be offered as soon as possible after the event; 
offer alternatives or ask the learner to do so; look forward to the specific next steps to improve performance; encourage and plan for opportunities for the feedback to be used as soon as possible; involve the learner wherever possible, to improve the chance of feedback being understood and acted upon'(p.56).

Thus in our practice, we should try our best to give feedback according to the above suggestions. We, in particular, should value the last point "involve the learner wherever possible, to improve the chance of feedback being understood and acted upon" because this was seen to have had a positive impact on students' ability to take control over their learning, enabling them to be continually reflective and analytical. As Rick Stiggins' (cited in Olson, 2005, p. 8) put it "...students make decisions [based on assessments] all the time, and they're critical," and those decisions range from "Can I learn this, or am I just too stupid?" to "Is the learning worth the energy I must expend to attain it?" Much of the information about how well they are doing will come as feedback from the teacher, but some will be through their direct involvement in assessing their own work.

\section{E. Evaluating and Revising the Assessment Plan}

In order for FA to achieve better results in later use, we should evaluate and revise the plan into a more practical one after implementing it. We should try to obtain relevant information about the efficacy of each item through a variety of channels such as observations, face-to-face interviews with students, specially designed questionnaire surveys, students' learning portfolios. For example, at the end of the second semester, I asked students to give a tick to every learning technique used in the very semester in corresponding box labeled "strongly agree" "agree" "Not always agree" "not agree". While evaluating, we first asked ourselves such questions as "Were students motivated and involved to do the tasks?" "Were they learning?", then synthesized the information from different sources. In this way, combined with teacher-student negotiation, a new assessment plan for subsequent learning stage will be significantly formulated. At plan making stage, we always bear in mind "successful learning occurs when learners have ownership of their learning; when they understand the goals they are aiming for; when, crucially, they are motivated and have the skills to achieve success" (Beyond the Black Box, ARG, 1999, p. 2), and in the process of adoption of formative assessment, we tried to involve students in every step because they are "ultimately responsible for their own learning and no one else can do it for them" (Beyond the Black Box , ARG, 1999, p. 2). So, evaluating the assessment plan is a necessary and worthwhile step.

\section{CONCLUSION}

Theoretically and empirically, FA proves to be "assessment for learning", and is even seen as"a new learning style" as most of my students do. In this article, I have just described and discussed the implementing guidelines and procedures of FA, mainly out of my own practice. For its effective impact on learning in other settings, there is still much to research.

\section{APPENDIX FINAL FA REPORT SAMPLES}

1. Final Formative Assessment Achievement Report (for students)

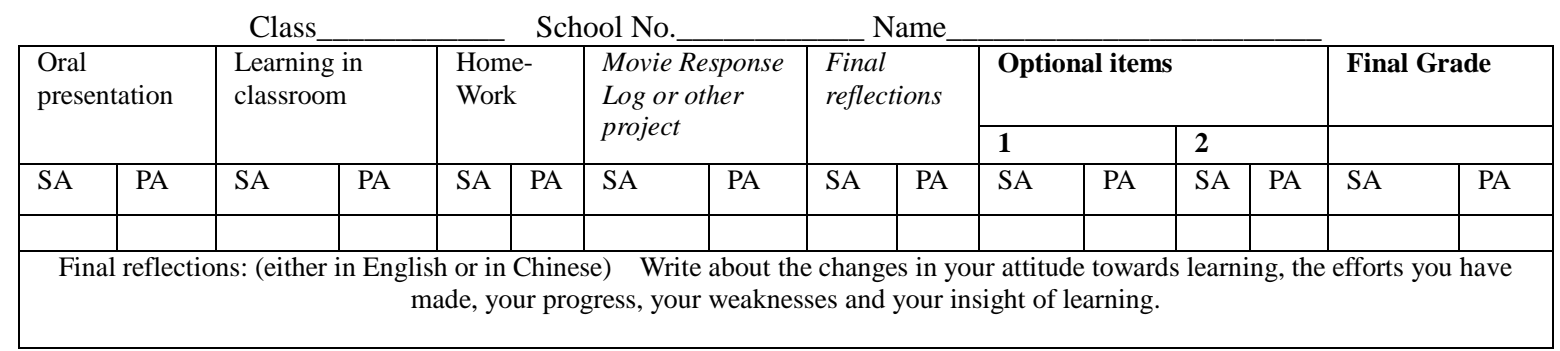

Directions:

1. $\mathrm{SA}=$ self assessment, $\mathrm{PA}=$ peer assessment

2. Letter Grading system--E, V, G, S, F( E=Excellent, V= Very Good, G=Good, $S=$ satisfactory, F=Fair) is preferable for each item.

3. Things to be considered when grading each item:

Oral presentation: written by oneself? How's the content? How are the presentation skills?

Learning in Classroom: attitude? attendance? Participation and involvement? linguistic competence(quizzes)?

Homework: done? whether self-corrected?

Movie response/ or project-based writing: language? contents?

Final reflections: comprehensiveness? Attitude?

Optional items: done? how many items? any document?

2. Final Formative Assessment Achievement Report (for Teachers) 


\begin{tabular}{|l|l|l|l|l|l|l|l|}
\multicolumn{9}{c}{ Class } & \multicolumn{2}{c}{ School No. Name } & \multicolumn{2}{l}{$\begin{array}{l}\text { Final Grading } \\
\text { (FG) }\end{array}$} \\
\hline $\begin{array}{l}\text { Oral } \\
\text { presentation }\end{array}$ & $\begin{array}{l}\text { Learning in } \\
\text { classroom }\end{array}$ & $\begin{array}{l}\text { Home- } \\
\text { work }\end{array}$ & Testing & Movie Response Log & Optional Items & \\
\hline & & & & & & & \\
\hline
\end{tabular}

Directions:

Final Grading (FG) is given by the teacher by integrating students learning portfolios and the results of self assessment and peer assessment from the students final formative achievement report. Each item is first given in letter form E, V, G, S, F (E=Excellent, V=Very Good, G=Good, S=satisfactory, F=Fair) and the final grading will be then transferred into marks. If FG is $\mathrm{E}$, the marks will be 95 ; if $\mathrm{V}$, marks will be 85 ; if $\mathrm{G}$, marks will be 80 ; if $\mathrm{S}$; marks will be 75 ; if F, marks will be 65 and below. The final mark will cover $50 \%$ of the semester scoring.

\section{REFERENCES}

[1] Assessment Reform Group, U.K. (1999). Assessment for learning: beyond the black box. Cambridge. U.K: University of Cambridge School of Education.

[2] Black, P., \& William, D. (1998a). Assessment and classroom learning. Assessment in Education, 5 (1): 7-74.

[3] Black, P. and William, D. (1998b). Inside the black box: Raising standards through classroom assessment. Phi Delta Kappan, 80 (2): 139-148. (Available online: http://www.pdkintl.org/kappan/ kbla9810.htm.)

[4] Crooks, T. J. (1988). The impact of classroom evaluation practices on students. Review of Educational Research, 58, $438-481$.

[5] Gibbs, G. \& Simpson, C. (2004). Does your assessment support your students' learning? Journal of Teaching and Learning in Higher Education (on-line), 1, 3-31. Retrieved from: http://www.glos.ac.uk/adu/clt/lathe/issue1/index.cfm.

[6] Gipps, C., McCallum, B., \& Hargreaves, E. (2000). What makes a good primary school teacher? London: Routledge Falmer.

[7] Guo, Q. \& Yang, zhi. Q. (2003). Formative Assessment and College English Teaching and Testing (In Chinese), Research On Education Tsinghua University, Vol.24, NO 5, pp103-108.

[8] Ministry of Education, New Zealand. (1994). Assessment: policy to practice. Wellington, New Zealand: Learning Media.

[9] Olson, L. (2005). Classroom Assessments Stir Growing Global Interest. Education Week. Washington: October 5, 2005.Vol. 25, Iss.6, p.8.

[10] Pausch, L.M. \& Popp, M.P. (1997). Assessment of Information Literacy: Lessons from the Higher Education Assessment Movement. Retrieved October 30, 2001, from http://www.ala.org/acrl/paperhtm/d30.html

[11] Sutton, R. (1998). School-wide Assessment. Improving Teaching and Learning. New Zealand Council for educational Research. Wellington NZ.

[12] Tan, H. Y. (2004). Using Formative Assessment Strategies to Aid Students' Learning in Adult English Teaching as Foreign Language-An Experimental Study.

[13] Xue, M. (2006). A study of Formative Assessment in College EFL Learning and Teaching.

[14] Xu, B.X. (2003). On the Formative Assessment of EFL Students: From Theory to Practice.

[15] Zou, H. M. \& Cai, Zh. Y. (2006). An Experiment on Implementation of Formative Assessment and the Reform of the Current Assessing System of College English Teaching (in Chinese), Journal of Jiangxi Normal University(Philosophy and Social Sciences Edition), VoL. 39 (1): 114-118.

Liqiu Wei was born in Guangxi, China in 1967. She received her M.A. degree in linguistics from Guangdong University of Foreign Studies, China in 2008.

She is currently an associate professor in the department of Foreign Languages, Hechi University, Guangxi, China. Her research interests include English language teaching, second language acquisition and foreign language teacher development. 